
\title{
R Reserach S Suare \\ Determinants of under nutrition among the elderly in South Gondar Zone, Ethiopia
}

\author{
Debre Tabor University \\ Ismael Maru \\ Debre Tabor University \\ Misganaw Abie \\ Debre Tabor University \\ Getachew Aragie \\ Debre Tabor University \\ Amien Ewunetei \\ Debre Tabor University \\ Melkalem Mamuye \\ Debre Tabor University \\ Fentaw Teshome \\ Debre Tabor University
}

Hiwot Yisak ( $\nabla$ hyisak@yahoo.com )

\section{Research Article}

Keywords: Elderly, under nutrition, Determinants, South Gondar, Ethiopia

Posted Date: April 22nd, 2021

DOl: https://doi.org/10.21203/rs.3.rs-449391/v1

License: (1) (1) This work is licensed under a Creative Commons Attribution 4.0 International License.

Read Full License 


\section{Abstract}

Background: The number of the elderly population is expected to become the largest demographic group. Malnutrition in older adults is related with complications and premature death. The progression to malnutrition is often insidious and often undetected. No study has been ever conducted or documented to explore the nutritional status of elderly in south Gondar Zone. Hence, this study was aimed to assess the determinants of under nutrition among the elderly people aged $\geq 65$ years. A cross-sectional study was conducted from October 1 to December 15, 2020. A community based study was conducted in south Gondar Zone, Ethiopia. A total of 290 elderly aged greater or equal to 65 years of age selected by systematic random sampling technique were included in the study. Pretested and structured questionnaire adapted from different literature was used to collect data. Anthropometric measurements; weight and height were measured following standard procedures. Mini-Nutritional Assessment (MNA) tool was used to assess nutritional status of elderly. Descriptive and summary statistics were employed. Multiple logistic regression was fitted to identify determinants of under nutrition. Odds ratios and their $95 \%$ confidence intervals were computed to determine the level of significance.

Results: Based on their BMI status $27.57 \%, 95 \% \mathrm{Cl}(22.4-32.8)$ of elderly were underweight and $2.1 \%, 95 \%$ $\mathrm{Cl}(0.7-3.8)$ were overweight. Likewise, $29.7 \%, 95 \% \mathrm{Cl}(24.5-35.2)$ of elderly were malnourished and $61.7 \%$, $95 \% \mathrm{Cl}$ (55.5-67.2) were at risk of malnutrition based on Mini-Nutritional Assessment tool. Rural residence $(A O R=10.32,95 \% \mathrm{Cl}(3.62-29.39))$, unable to read and write $(A O R=3.54,95 \% \mathrm{Cl}(1.64-7.64))$, decline in food intake $(A O R=13.47,95 \% \mathrm{Cl}(6.14-29.52))$ and household monthly income $<35.6$ USD (AOR $=4.32$, $95 \% \mathrm{Cl}(1.97-9.46))$ were significantly and independently associated with under nutrition in elderly population.

Conclusion: The prevalence of under nutrition among the elderly in the study area was high, and making it an important public health burden. Place of residence, educational status, food intake and household income were the determinants of under nutrition.

\section{Introduction}

The world has seen significant growth in the number of the elderly and anticipated to become the largest demographic group in the next few years. As per to the United Nations, in 2025, it is expected that the number of people $\geq 60$ years of age will be 1.2 billion and 2 billion in 2050 taking about $22.0 \%$ of the world's population (1). High number of elderly gives an understanding to reevaluate the suitability of health infrastructures for the elderly. Eleven percent of the world population and 3.2\% of Ethiopian population is categorized under elderly population aged $\geq 65$ years (2). Anthropometric measurements are pointers that help determine one's nutritional status. The well-known and applied anthropometric assessment in older adults is the Body Mass Index (BMI) (3).

Malnutrition may be as a result of lack of nutrients (under-nutrition), or an excess of nutrients (overnutrition) (4). A physiologic deterioration in food intake is seen among the elderly due to change in 
neurotransmitters and hormones that affect the central feeding drive (5-7). Loss of lean body mass and the low metabolic rate in elderly may impact appetite and food intake. Decrement in sensation both olfaction and taste decreases the enjoyment of food, leads to reduced intake of diversified food. Underlying pathology and medical treatment can cause anorexia and malnutrition (8). Chronic illness among the elderly are treated with medications and dietary restriction that affects food intake. Drugs also affect nutritional status through its side effects and through change of nutrient absorption, metabolism and excretion (9). Weight loss in older adults is often related with a loss of muscle mass and can finally affect functional status. Malnutrition in older adults is related with complications and premature life loss(10). The advancement to malnutrition is mostly treacherous and often unnoticed. On the other hand, restriction of mobility and sedentary lifestyle make them overweight and obese (11). Concerning the current corona virus (COVID -19) pandemic, studies have demonstrated that elderly patients with COVID19 are at greatest risk of malnutrition or co-malnutrition. Additionally, COVID-19 can affect the mucosal epithelium and cause gastrointestinal symptoms, which can additionally damage the nutritional status of elderly patients with COVID-19 (12). The price of health cost which is related associated with treating the infection and/or malnutrition is high (13). The health and nutrition of the elderly is usually ignored; many of the intervention activities are directed toward neonates, children, adolescents, expectant and nursing mothers. As far as the authors' best search, no study has been ever conducted or documented to determine the nutritional status and its determinants among these segments of the population in South Gondar Zone thus far (14). Therefore, understanding the cause of under nutrition among older people has utmost importance to arrest the problem. Hence, this study was carried out to determine the magnitude and determinant factors of under nutrition among people aged $\geq 65$ years in south Gondar Zone, Ethiopia.

\section{Methods}

\section{Study area, design and period}

The study was conducted in South Gondar Zone. South Gondar is a Zone in the Ethiopian Amhara Region. Based on the 2007 Census conducted by the Central Statistical Agency of Ethiopia (CSA), this Zone has a total population of 2,051,738. With an area of 14,095.19 square kilometers, South Gondar has a population density of $145.56 ; 195,619$ or $9.53 \%$ are urban inhabitants. A total of 468,238 households were counted in this Zone, which results in an average of 4.38 persons to a household. There are 96 health centers, 7 primary hospitals, and 1 general hospital in the zone. According to the 2011 CSA, South Gondar zone has a total population of, 2,239,077 (female 1,103,490 male1, 135,587). And $2.8 \%$ of the total population is expected to be above the age of 65 years. A community based cross-sectional study was conducted from October 1- December 15, 2020.

\section{Study participants, sample size and sampling techniques}

All old people aged $\geq 65$ years old who were living in 3 randomly selected woredas of South Gondar Zone at the time of data collection were the study population. Those who were critically ill and those mentally 
incompetent were excluded from the study. The sample size was calculated using single population proportion formula. Taking the prevalence of under nutrition $21.9 \%$ (14), margin of error of $5 \%, Z$ value of 1.96 and taking $10 \%$ non-response rate the final sample size was 290 . First three woredas (geographic sub divisions of a Zone) were selected by lottery method from a total of 18 woredas; then census was conducted to enumerate the total number of elderly in each woredas. Then the calculated sample was allocated to each Woredas proportionally based on the number of elderly. Finally, systematic random sampling technique was used for the selection of individual respondents.

\section{Measurements}

\section{Assessment of under nutrition}

The outcome variable, under nutrition was measured using Mini Nutritional Assessment (MNA) tool developed by Nestle Nutrition Institute. The MNA tool was validated in developing setting including Ethiopia (15). Based on MNA scores, elderly is categorized into non-malnutrition group (MNA 12-14), the group with risk of malnutrition (MNA of 8-11) and malnutrition group (MNA score $\leq 7$ ) (16). In addition, $\mathrm{BMI}$ was calculated to determine the nutritional status of elderly. Arm span was used as a proxy measure for height in elderly. Thus, body mass index (BMI) was estimated as the weight in $\mathrm{kg}$ divided by arm span in meters squared $\left(\mathrm{kg} / \mathrm{m}^{2}\right)$. Obesity was defined $\geq 30.0 \mathrm{~kg} / \mathrm{m} 2$., overweight was defined as 25.0 $\mathrm{kg} / \mathrm{m}^{2} \leq \mathrm{BMl}<29.9 \mathrm{~kg} / \mathrm{m}^{2}$ and underweight was defined as BMl of less than $18.5 \mathrm{~kg} / \mathrm{m} 2(4,13)$.

\section{Anthropometric measurements}

Weight was measured in light clothes with bare feet using a beam scale (Seca ${ }^{\circledR}$, Germany). Arm span was measured between the middle figure of one hand to the middle figure of other hand using a measuring tape (Seca ${ }^{\circledR}$, Germany). The height and arm span accuracy were $0.1 \mathrm{~cm}$. The anthropometric measurements were measured following a standard procedure (17). All measurements were done in twice, and the average value was used for analyses.

\section{Assessment of predictors}

In addition to anthropometric measurements and MNA assessment, place of residence, gender, age, economic status, marital status, occupation, educational status, illness in the past three months, food intake status, presence of known chronic disease, current medication intake, physical activity, dietary habits, $24 \mathrm{hr}$ dietary diversity score and alcohol consumption was assessed. The age of the elderly was defined as age $\geq 65$ years .Dietary diversity score was detected using 24 dietary recall method. Dietary diversity as categorized into poor (those who consumed less than 5 food groups out of 9 food groups) and good (those who consumed 5 or more food groups out of 9 food groups). Physical activity was defined as doing any activities or exercise for more than 30 minutes (18).

Pretested and structured questionnaires using face-to-face interviewing with participants were used for data collection. The questionnaire was adapted from food and agriculture organization of united 
nation (19). Data were collected by three diploma nurses and supervised by two public Health officers. A two days comprehensive training was given to data collectors and supervisors. The questionnaire was first prepared in English and then translated into Amharic (the local language), and back into English to ensure consistency. To ensure the quality of the data, every day the questioner was reviewed for completeness, accuracy and clarity by the principal investigator.

\section{Data processing and analysis}

The questionnaires were coded and entered into Epidata version 3.1 statistical software and then exported to SPSS windows version 25 for further analysis. Data were summarized and presented using descriptive statistics. Bi- variate and multiple logistic regressions were computed to identify the presence and strength of associations. Odds ratios with $95 \% \mathrm{Cl}$ were computed and variables having $\mathrm{p}$-values less than 0.05 in the multiple logistic regression models were considered significantly associated with the outcome variable.

\section{Results}

\section{Socio demographic and economic related characteristics of participants}

A total of 290 elderly participated in the study giving response rate of $100.0 \%$. The mean ( \pm SD) age of participants was 68.54 (4.19) years. Most of them were aged 65-69 years, $52.28 \%(169)$. Among the study participants more than half of them were female $55.86 \%$ (162).

Concerning place of residence, $64.14 \%$ (186) of the participants were from rural areas and $58.62 \%(170)$ of participants were married regarding to their marital status. When we see their educational status, $45.51 \%$ (132) were unable to read and write. Concerning economic dependency, $52.76 \%$ (153) of the respondents were partially dependent economically and $47.57 \%$ (138) were farmer before retirement. Regarding monthly income, $52.41 \%$ (152) of the participants had low monthly income (Table 1).

\section{Health and life style characteristics}

About $73.79 \%$ (214) of the respondents had a history of known chronic illness during the interview. Nearly half, $48.62 \%$ (141), of the participant had a complaint of illness in the past 3 months before the interview. Concerning the types of chronic diseases, $32.72 \%$ (70) had hypertension and $23.81 \%(51)$ had heart failure. Regarding alcohol intake and cigarette smoking, $60.00 \%$ (174) took alcohol and among them $74.71 \%$ (130) took alcohol on daily basis but there was no cigarette smoker. Among the study participants $23.79 \%$ (69) of them took soft drink and other sugary foods once or twice per week; and the rest $76.21 \%$ (221) took occasionally. About $26.21 \%$ (76) of participants consumed meat and other fatty foods (butter and milk products) 1-3 times per week, $6.90 \%$ (20) consumed daily, the rest $66.90 \%$ (194) uses occasionally.

About $81.72 \%$ (237) of the participants do physical activity and among this majority $(75.53 \%(179))$ of them do walking followed by walking and harvesting $23.63 \%$ (26) and fetching water $0.84 \%$ (2). From 
the total participants, $38.28 \%$ (111) of them were suffering from decline in food intake in the last three months and most $(97.30 \%(108)$ ) of them mentioned loss of appetite as a reason. Among the study participants, $48.28 \%$ (140) took medication; among them $66.43 \%$ (93) took one or two medications (Table 2).

\section{Dietary diversity characteristics}

The most commonly consumed food groups in the last 24 hours were legumes and nut $75.86 \%(220)$ followed by cereals and roots $51.72 \%$ (150) and dark green vegetables $46.55 \%$ (135). Regarding the dietary diversity score (DDS), 10.69 \% (31) scored well and $89.31 \%$ (259) scored poor (Table 3).

\section{Nutritional status of elderly}

According to this study, the overall prevalence of under nutrition among the participants was $27.57 \%(80)$ while majority $70.34 \%$ (204) had normal BMI and only $2.07 \%$ (6) of them were overweight. As per mini nutritional assessment tool, $8.6 \%$ (25) were having normal nutritional status, $61.7 \%$ (179) were at risk of malnutrition and $29.7 \%$ (86) of elderly are malnourished.

\section{Factors associated with under nutrition}

On bivariate logistic regression; residence (living in rural area), sex, not being married, being unable to read and write, illness in the last three months, known chronic illness, decline in food intake and household monthly income $<35.6$ USD were positively associated with under nutrition. Whereas, residence (living in rural area), being unable to read and write, decline in food intake and household monthly income $<35.6$ USD were remained significantly associated with under nutrition on the multivariable logistic regression. The odds of under nutrition was more than 12 times higher among elderly who have history of decline in food intake (AOR $=13.471,95 \% \mathrm{Cl}$ : 6.147-29.525). This study also showed that elderly whose monthly income less than 35.6USD were 4.3 times (AOR $=4.319,95 \% \mathrm{Cl}: 1.971-9.460)$ more likely to be undernourished than their counterparts. Also, being unable to read and write increased the odds of under nutrition among the study participants (AOR $=3.542,95 \% \mathrm{Cl}$ : $1.642-7.643)$. Study participants who lived in rural area were more than 10 times to be undernourished than those from urban area (AOR=10.320, 95\%Cl: 3.624-29.390) (Table 4).

\section{Discussion}

The overall prevalence of under nutrition was $27.57 \%$. This finding is comparable with the studies done in Nepal 24.8\% (95\% Cl:20.21-29.30) (20). However, it was higher than that of the studies done in Wolaita Zone Ethiopia 17.1\% (21), Northwest Ethiopia 21.9\% (22), Ethiopia 17.6\% (95\% Cl: 15.00, 20.20) (23), Cameron 6\% (24), Delhi India 20.8\% (25). This difference could be due to geographical difference, variation in socio-economic status of study population. In addition in the current study most of the study participants were from rural area which might be associated with lower food buying power of participants 
to diversified food items. On the other hand, the prevalence of under nutrition was lower as compared to study done in Ghana $48.0 \%$ (24).

In this study, the prevalence of under nutrition was high among females $20.34 \%$ compared to males $7.23 \%$.In agreement with this, a study from Gondar found that being female (AOR= $3.0,95 \% \mathrm{Cl}$ (1.65.4)) was associated with under nutrition(22). Similarly a study which assessed chronic energy deficiency and associated factors among older population in, Aykel town, Ethiopia in 2018 showed that under nutrition was significantly associated with female sex $(A O R=1.58,95 \% \mathrm{Cl}(1.04,2.41)(23)$. This might be because most female elderly were economically dependent, gender discriminations and less health seeking behavior, which may negatively influence women's health and nutritional status.

This study pointed out that $89.31 \%$ of the elderly had poor dietary diversity score. This might be due to the study was conducted during fasting period, most of the participants were economically dependent and most of them were unable read and write.

This study has revealed that $25.52 \%$ of rural elderly people were malnourished in that participants who lived in rural areas were more than 10 times more likely to be undernourished than those from urban area. Thus, it appears that under nutrition is much higher among the elderly residing in the rural areas. This finding is consistent with the results of studies conducted in wolaita zone Ethiopia (21), Northwest Ethiopia (22) and Ethiopia (23).

In the current study monthly income of less than 35.6USD had significant association with under nutrition. Similarly studies done in wolaita Zone Ethiopia (21), Northwest Ethiopia(22) and Ethiopia(23) showed that low income had negative effect on nutrition status of elderly. This might be due to food purchasing ability depends on the level of incomes and low income may make elderly to prefer not to eat.

Decreased food intake was positively associated with under nutrition. This could be due to the effects of increased age which reduces the natural drive to eat and drink and resulting in anorexia of aging; to their comorbid illness of which most of them had chronic illness and; to the medication they took since most of them took medications. This finding was similar to a study conducted in Wolaita Zone Ethiopia (21).

This study pointed out being unable to read and write was 3.5 times (AOR $=3.542,95 \% \mathrm{Cl}: 1.642-7.643$ ) more likely to be undernourished than those who can read and write. This finding is consistent with the results of earlier studies conducted in Wolaita Zone Ethiopia (21) and in Northwest Ethiopia(22) . This might be related to the fact that educated people are more likely to consume diversified food and follow healthy eating style.

\section{Strength of the study}

The study was community based and it can represent the population.

\section{Limitation of the study}


The study did not assessed micronutrient level and fat composition of elderly.

\section{Conclusion}

The overall prevalence of under nutrition among the elderly in the study area was high making important public health burden. It was significantly associated with residence, being unable to read and write, decline in food intake and household monthly income. Therefore, there is a need to design and implement programs and strategies to improve nutritional status particularly focusing on female older population, those living in rural area and improving household economic status. For this, further studies are needed to generate a database for effective policy making and formulate a national policy on the nutrition of the elderly to ensure healthy aging.

\section{List Of Abbreviations And Acronyms}

BMI

CDC

$\mathrm{Cl}$

COVID-19

CSA

DDS

ETB

GC

$\mathrm{MCH}$

NICU

OPD

OR

SARS - Cov 2

SD

SPSS

WC
Body Mass Index

Centre for Disease Control

Confidence Interval

Virus Disease of 2019.

Central Statistical Agency

Dietary Diversity Score

Ethiopian Birr

Gregorian Calendar

Mother and Child Health

Neonatal Intensive Care Unit

Outpatient Department

Odds Ratio

Severe Acute Respiratory Syndrome Corona virus 2

Standard Deviation

Statistical Package for Social Science

Waist Circumference 


\section{Declarations}

\section{Ethics approval and consent to participate}

This study have been performed in accordance with the Declaration of Helsinki. Ethical clearance was obtained from Debre Tabor University College of medicine \& health science ethical review committee. Then, the participants of the study were informed about the purpose of the study, the importance of their participation, and their right to withdraw at any time. All methods were carried out in accordance with ethical guidelines and regulations. Informed consent was obtained prior to data collection. To keep the confidentiality of clients' data, their names was not document. People aged $\geq 65$ who were malnourished during the data collection were advised regarding their nutrition.

\section{Consent to publish}

All the authors have agreed and gave consent for the publication

\section{Availability of data and materials}

The datasets used during the current study are available from the corresponding author on a reasonable request.

\section{Competing of interest}

All authors declared that there is no competing interest at all.

\section{Funding statement}

The author(s) received no financial support for the research, authorship, and/or publication of this article.

\section{Authors' contributions}

HY, IM and MA made substantial contributions to conception and design, acquisition of data, or analysis and interpretation of data. GA, AE, MM and FT took part in drafting the article or revising it critically for important intellectual content. All authors agreed to submit to the current journal; gave final approval of the version to be published; and agree to be accountable for all aspects of the work.

\section{Acknowledgement}

The authors would like to thank the participants of the study and officials in South Godar Zone.

\section{References}


1. Jennings A, Tang J, Gillings R, Perfecto A, Dutton J, Speakman J, et al. Changing from a Western to a Mediterranean-style diet does not affect iron or selenium status: results of the New Dietary Strategies Addressing the Specific Needs of the Elderly Population for Healthy Aging in Europe (NU-AGE) 1-year randomized clinical trial in elderly Europeans. The American journal of clinical nutrition. 2020;111(1):98-109.

2. Charles T AH, Tesfayi G, Hassan A. Population Dynamics,Food/Nutrition Security and Health in Ethiopia. Delicate Balance of Vulnerability \& Resilience IUSSP Marrakech; . 30 Sept 2009.

3. Abbes MAaKB-R, . ., . Obesity increases blood pressure in North-African elderly subjects. . Pak J Nutr. 2018;17:: 152-5.

4. Organization) WWH. Nutrition disorders.

5. Evans C. Malnutrition in the elderly: a multifactorial failure to thrive. The Permanente Journal. 2005;9(3):38.

6. Morley JE. Pathophysiology of anorexia. Clinics in geriatric medicine. 2002;18(4):661-73, v.

7. Huffman GB. Evaluating and treating unintentional weight loss in the elderly. American family physician. 2002;65(4):640.

8. Bouras EP, Lange SM, Scolapio JS, editors. Rational approach to patients with unintentional weight loss. Mayo Clinic Proceedings; 2001: Elsevier.

9. Chen $\mathrm{CCH}$, Schilling LS, Lyder $\mathrm{CH}$. A concept analysis of malnutrition in the elderly. Journal of advanced nursing. 2001;36(1):131-42.

10. M. H. Malnutrition and ageing. Postgrad Med J. 2006;82(963):2-8.

11. Hsiao PY, Mitchell, D. C., Coffman, D. L., Wood, G. C., Hartman, T. J., Still, C., \& Jensen, G. L. . Dietary patterns and relationship to obesity-related health outcomes and mortality in adults 75 yeas of age or greater. The Journal of Nutrition, Health \& Aging. 2013; 17:566-72.

12. Huang $C$ WY, Li X, Ren L, Zhao J, Hu Y, et al. . Clinical features of patients infected with novel coronavirus in Wuhan, China. Lancet 2020;395:497-506.

13. Malnutrition in the Older Adult [Internet]. 2010. Available from: http://www.nestle.com/assetlibrary/documents/.

14. Agarwalla R, Saikia AM, Baruah R. Assessment of the nutritional status of the elderly and its correlates. Journal of family \& community medicine. 2015;22(1):39.

15. Hailemariam $H$, Singh $P$, Fekadu T. Evaluation of mini nutrition assessment (MNA) tool among community dwelling elderly in urban community of Hawassa city, Southern Ethiopia. BMC Nutrition. 2016;2(1):1-6.

16. t. NNI. MNA® Mini Nutritional Assessmen. 2009.

17. Harris D, Haboubi N. Malnutrition screening in the elderly population. Journal of the Royal Society of Medicine. 2005;98(9):411-4.

18. Muchiri WA, Olutende OM, Kweyu IW, Vurigwa E. Meaning of physical activities for the elderly: A review. American Journal of Sports Science and Medicine. 2018;6(3):79-83. 
19. Food and agriculture organization of the united nations F. dietary assessment a resource guide to method selection and application in low resource settings. 2018.

20. Man Kumar Tamang1 UNY, 3* , Hassan osseinzadeh3, Bharat Kafe4, Girish Paudel2, Saroj Khatiwada5 and Varalakshmi Chandra Sekaran. Nutritional assessment and factors associated with malnutrition among the elderly population of Nepal: a cross-sectional study BMC. 2016.

21. Kidest Wondiye1 NAA, Tsegaye Demisse Gemebo3 and Feleke Hailemichael Astawesegn2. Predictors of undernutrition among the elderly in Sodo zuriya district Wolaita zone, Ethiopia. BMC Nutrition. 2019.

22. Tessfamichael D GA, Wassie MM. High Prevalence of Undernutrition among Elderly People in Northwest ,A Cross Sectional Study. J Nutrition Health Food Sci 2014 2(3):1-5.

23. Legesse M AZ, Woldie H, . Chronic energy deficiency and associated factors among older population in Ethiopia: A community based study. . PLoS ONE. 2019.

24. organization. WH. Health Situtation and trend assessment- Elderly Population. 2019.

25. Goswami AK NB, Kalaivani M, Gupta SK, Pandav CS.. Double burden of malnutrition among elderly population of Delhi. . Indian J Comm Health. 2016; 28 (4):324-30.

\section{Tables}

Table 1 Socio-demographic and economic characteristics of elderly in South Gondar Zone, Amhara, Ethiopia. 


\begin{tabular}{|c|c|c|c|}
\hline Variable & & Frequency & Percentage \\
\hline \multirow[t]{3}{*}{ Residence } & Urban & 104 & 35.86 \\
\hline & Rural & 186 & 64.14 \\
\hline & Total & 290 & 100.00 \\
\hline \multirow[t]{3}{*}{ Sex } & Male & 128 & 44.14 \\
\hline & Female & 162 & 55.86 \\
\hline & Total & 290 & 100.00 \\
\hline \multirow[t]{5}{*}{ Age } & $65-69$ & 169 & 58.28 \\
\hline & $70-74$ & 95 & 32.76 \\
\hline & $75-79$ & 13 & 4.48 \\
\hline & $>=80$ & 13 & 4.48 \\
\hline & Total & 290 & 100.00 \\
\hline \multirow[t]{5}{*}{ Marital status } & Currently married & 170 & 58.62 \\
\hline & Single & 2 & 0.69 \\
\hline & Separated & 17 & 5.86 \\
\hline & Widowed & 101 & 34.83 \\
\hline & Total & 290 & 100.00 \\
\hline \multirow[t]{4}{*}{ Economic dependence } & Partially dependent & 153 & 52.76 \\
\hline & Fully dependent & 127 & 43.79 \\
\hline & Independent & 10 & 3.45 \\
\hline & Total & 290 & 100.00 \\
\hline \multirow[t]{6}{*}{ Occupation before retirement } & Housewife & 84 & 28.97 \\
\hline & Self employed & 46 & 15.86 \\
\hline & Farmer & 138 & 47.57 \\
\hline & Nongovernment employee & 4 & 1.38 \\
\hline & Government employee & 18 & 6.21 \\
\hline & Total & 290 & 100.00 \\
\hline
\end{tabular}




\begin{tabular}{|c|c|c|c|}
\hline \multirow[t]{6}{*}{ Current occupational status } & Retired & 172 & 59.31 \\
\hline & Housewife & 42 & 14.48 \\
\hline & Self employed & 13 & 4.48 \\
\hline & Farmer & 62 & 21.38 \\
\hline & Nongovernment & 1 & 0.34 \\
\hline & Total & 290 & 100.00 \\
\hline \multirow[t]{5}{*}{ Educational status } & Cannot write and read & 132 & 45.52 \\
\hline & Read and write with no formal education & 114 & 39.31 \\
\hline & Primary education & 24 & 8.28 \\
\hline & College and above & 20 & 6.90 \\
\hline & Total & 290 & 100.00 \\
\hline \multirow[t]{4}{*}{ Monthly household income } & Low (<35.6USD) & 152 & 52.41 \\
\hline & Middle (35.6USD -106.8USD) & 88 & 30.35 \\
\hline & High (>106.8USD) & 50 & 17.24 \\
\hline & Total & 290 & 100.00 \\
\hline
\end{tabular}

Table 2 Health and Life style characteristics of elderly in South Gondar Zone, Amhara, Ethiopia 2020 


\begin{tabular}{|c|c|c|c|}
\hline Variable & & Frequency & Percentage \\
\hline \multirow[t]{3}{*}{ Illness in the past three months } & Yes & 141 & 48.62 \\
\hline & No & 149 & 51.38 \\
\hline & Total & 290 & 100.0 \\
\hline \multirow[t]{10}{*}{ Known chronic illness $(n=214)$} & Hypertension & 70 & 32.71 \\
\hline & DM & 20 & 9.35 \\
\hline & Joint Pain & 28 & 13.08 \\
\hline & Heart Failure & 51 & 23.81 \\
\hline & Asthma & 17 & 7.94 \\
\hline & HIV & 5 & 2.24 \\
\hline & Liver Disease & 3 & 1.40 \\
\hline & Other & 20 & 9.35 \\
\hline & None & 76 & 26.21 \\
\hline & Total & 290 & 100.0 \\
\hline \multirow[t]{3}{*}{ Family history of obesity } & Yes & 1 & 0.34 \\
\hline & No & 289 & 99.66 \\
\hline & Total & 290 & 100.0 \\
\hline \multirow[t]{3}{*}{ Alcohol consumption } & Yes & 174 & 60.0 \\
\hline & No & 116 & 40.0 \\
\hline & Total & 290 & 100.0 \\
\hline \multirow[t]{6}{*}{ Frequency $(n=174)$} & Daily & 130 & 74.71 \\
\hline & 5-6 days per week & 10 & 5.75 \\
\hline & 1-4 days per week & 20 & 11.49 \\
\hline & 1-3 days per month & 14 & 8.04 \\
\hline & once per month & 1 & 0.57 \\
\hline & Total & 290 & 100.0 \\
\hline \multirow[t]{3}{*}{ Physical activity } & Yes & 237 & 81.72 \\
\hline & No & 53 & 18.28 \\
\hline & Total & 290 & 100.0 \\
\hline
\end{tabular}




\begin{tabular}{|c|c|c|c|}
\hline \multirow[t]{4}{*}{ Which one $(n=237)$} & Walking & 179 & 75.53 \\
\hline & Fetching & 2 & 0.84 \\
\hline & Walking and harvesting & 56 & 23.63 \\
\hline & Total & 237 & 100.0 \\
\hline \multirow[t]{3}{*}{ Decline in food intake } & Yes & 111 & 38.28 \\
\hline & No & 179 & 61.72 \\
\hline & Total & 290 & 100.0 \\
\hline \multirow[t]{3}{*}{ Reason $(n=111)$} & loss of appetite & 108 & 97.30 \\
\hline & chewing problem & 3 & 2.70 \\
\hline & Total & 111 & 100.0 \\
\hline \multirow[t]{3}{*}{ Current medication usage } & Yes & 140 & 48.28 \\
\hline & No & 150 & 51.72 \\
\hline & Total & 290 & 100.0 \\
\hline \multirow[t]{3}{*}{ Number of medications $(n=140)$} & $\leq 2$ & 93 & 66.43 \\
\hline & $\geq 3$ & 47 & 33.57 \\
\hline & Total & 140 & 100.0 \\
\hline
\end{tabular}

Table 3 Consumption of the nine food groups by the study subjects in the last 24 hours in South Gondar Zone, Amhara, Ethiopia 2020 


\begin{tabular}{|c|c|c|c|}
\hline Variable & & Frequency & Percentage \\
\hline \multirow[t]{3}{*}{ Cereal and root } & Yes & 150 & 51.72 \\
\hline & No & 140 & 48.27 \\
\hline & Total & 290 & 100.0 \\
\hline \multirow[t]{3}{*}{ Dark green vegetable } & Yes & 135 & 46.55 \\
\hline & No & 155 & 53.45 \\
\hline & Total & 290 & 100.0 \\
\hline \multirow[t]{3}{*}{ Fruits and vegetable } & Yes & 107 & 36.90 \\
\hline & No & 183 & 63.10 \\
\hline & Total & 290 & 100.0 \\
\hline \multirow[t]{3}{*}{ Other vitamin A rich fruits and vegetables } & Yes & 49 & 16.90 \\
\hline & No & 241 & 83.10 \\
\hline & Total & 290 & 100.0 \\
\hline \multirow[t]{3}{*}{ Meat and fish } & Yes & 26 & 8.97 \\
\hline & No & 264 & 91.03 \\
\hline & Total & 290 & 100.0 \\
\hline \multirow[t]{3}{*}{ Organ meat } & Yes & 4 & 1.38 \\
\hline & No & 286 & 98.62 \\
\hline & Total & 290 & 100.0 \\
\hline \multirow[t]{3}{*}{ Legumes and nut } & Yes & 220 & 75.86 \\
\hline & No & 70 & 24.14 \\
\hline & Total & 290 & 100.0 \\
\hline \multirow[t]{3}{*}{ Milk } & Yes & 63 & 21.72 \\
\hline & No & 227 & 78.28 \\
\hline & Total & 290 & 100.0 \\
\hline \multirow[t]{3}{*}{ Egg } & Yes & 25 & 8.62 \\
\hline & No & 265 & 91.38 \\
\hline & Total & 290 & 100.0 \\
\hline Dietary diversity score & Good & 31 & 10.69 \\
\hline
\end{tabular}




\begin{tabular}{lll} 
Poor & 259 & 89.31 \\
\hline Total & 290 & 100.0
\end{tabular}

Table 4 : Factors associated with under nutrition among elderly in South Gondar Zone, Amhara, Ethiopia 2020

\begin{tabular}{|c|c|c|c|c|c|}
\hline \multirow[t]{3}{*}{ Variables } & & \multicolumn{2}{|c|}{ Under nutrition } & \multirow{2}{*}{\multicolumn{2}{|c|}{$95 \%$ C. I for OR }} \\
\hline & & \multirow{2}{*}{$\begin{array}{l}\text { Yes } \\
\text { Frequency }\end{array}$} & No & & \\
\hline & & & Frequency & $\begin{array}{l}\text { Bivariate } \\
\text { (COR) }\end{array}$ & $\begin{array}{l}\text { Multivariable } \\
\text { (AOR) }\end{array}$ \\
\hline \multirow[t]{2}{*}{ Education } & $\begin{array}{l}\text { Read and write } \\
\text { and above }\end{array}$ & 19 & 141 & 1 & 1 \\
\hline & $\begin{array}{l}\text { Cannot read and } \\
\text { write }\end{array}$ & 61 & 69 & $\begin{array}{l}6.561(3.637- \\
11.835)\end{array}$ & $\begin{array}{l}3.542(1.642- \\
7.643)\end{array}$ \\
\hline \multirow[t]{2}{*}{ Residence } & Urban & 6 & 99 & 1 & 1 \\
\hline & Rural & 74 & 111 & $\begin{array}{l}11.000(4.586- \\
26.387)\end{array}$ & $\begin{array}{l}10.320(3.624- \\
29.390)\end{array}$ \\
\hline \multirow{2}{*}{$\begin{array}{l}\text { Monthly } \\
\text { household } \\
\text { income }\end{array}$} & $<35.6$ USD & 58 & 94 & $\begin{array}{l}3.253(1.856- \\
5.702)\end{array}$ & $\begin{array}{l}4.319(1.971- \\
9.460)\end{array}$ \\
\hline & $\geq 35.6$ USD & 22 & 116 & 1 & 1 \\
\hline \multirow[t]{2}{*}{$\begin{array}{l}\text { Decline in food } \\
\text { intake }\end{array}$} & Yes & 68 & 43 & $\begin{array}{l}22.008(10.937- \\
44.285)\end{array}$ & $\begin{array}{l}13.471(6.147- \\
29.525)\end{array}$ \\
\hline & No & 12 & 167 & 1 & 1 \\
\hline
\end{tabular}

